\title{
ENTREVISTA COM CLARISSA JORDÃO
}

\section{Interview with Clarissa Jordão}

\author{
Francisco Carlos FOGAÇA (UFPR) ${ }^{1}$ \\ Denise, HIBARINO (UFPR) ${ }^{2}$ \\ Denise, KLUGE (UFPR) ${ }^{3}$ \\ Clarissa Menezes, JORDÃO (UFPR) ${ }^{4}$
}

A convidada desta entrevista, que inaugura uma nova seção na Revista X, é Clarissa Menezes Jordão. O tema da entrevista é naturalmente o Letramento Crítico (LC), uma vez que Clarissa foi uma das precursoras da perspectiva do LC no ensino de línguas estrangeiras no Brasil. Em um trabalho pioneiro realizado para a Secretaria de Estado da Educação do Paraná, em 2005, foi uma das autoras de um conjunto de materiais didáticos desenvolvidos para o ensino fundamental pautado no LC. Tal experiência é relatada no texto "Ensino de Inglês, Letramento Crítico e Cidadania: um triângulo amoroso bem-sucedido", publicado em 2007. Foi também uma das idealizadoras e fundadoras da Revista X, em 2006, tendo organizado uma edição totalmente dedicada ao Letramento Crítico ${ }^{5}$, em 2011.

O LC ganhou maior projeção na década de 1990, sendo amplamente discutido por autores como Lankshear e McLaren (1993), Morgan (1997), Luke (1997), Lankshear e Knobel (1998), Shor (1999), Cervetti et al (2001), mas com diferentes entendimentos do que vem a ser crítico. Shor (op. cit), por exemplo, filia-se à Pedagogia Crítica de Paulo Freire, de inspiração marxista, chamada por Souza (2011) de letramento crítico tradicional. Já autores como Cervetti et al (op. cit.) problematizam a noção de crítico utilizada na leitura crítica (ou letramento crítico tradicional) que busca ler a verdade oculta pela ideologia; esses autores questionam a possibilidade de acessarmos a realidade de forma objetiva, e consideram que a mesma seja construída

\footnotetext{
${ }^{1}$ Doutor em Estudos da Linguagem pela Universidade Estadual do Paraná; docente da UFPR

${ }^{2}$ Doutoranda em Linguística Aplicada pela UNICAMP.

${ }^{3}$ Doutora em Letras (Inglês e Literatura Correspondente) pela Universidade Federal de Santa Catarina; docente da UFPR

4 Doutora em Estudos Linguísticos e Literários em Inglês pela Universidade de São Paulo; docente da UFPR.

${ }^{5}$ Revista X, volume temático Letramento Crítico e Multiletramentos, publicado em 2011; http://revistas.ufpr.br/revistax/issue/view/1232/showToc .
} 
discursivamente, numa perspectiva pós-moderna. Ou seja, as coisas não são, simplesmente; elas são porque as vemos assim.

Entretanto, a maior parte dos textos produzidos nessa época ainda não eram voltados para o ensino de línguas estrangeiras, especificamente. Mas, autores como Bums e Hood (1998), Hammond e Macken-Horarik (1999), Brown (1999), buscavam pensar no LC para o de ensino e aquisição de segunda língua, assim como para a elaboração de atividades didáticas na sala de aulas de línguas.

Já faz mais de uma década que a perspectiva do Letramento Crítico no ensino de línguas estrangeiras vem sendo discutida por pesquisadores brasileiros (MONTE MOR, 2005; JORDÃO; FOGAÇA, 2007; SOUZA e ANDREOTTI, 2008; EDMUNDO, 2010; SOUZA, 2011; DUBOC, 2012, para citar apenas alguns), inclusive nas Orientações Curriculares para o Ensino Médio (BRASIL, 2006). Mais recentemente, O Guia de Livros Didáticos do Ensino Fundamental (2017) e do Ensino Médio (2016), do Programa Nacional do Livro Didático (PNLD), descrevem diversas coleções para o ensino de inglês e espanhol que se pautam pelo LC como orientador de atividades didático-pedagógicas. Os sentidos dados à noção de crítico, no entanto, são diversos. A seguir, apresentamos a entrevista que a Revista $\mathrm{X}$ realizou com Clarissa Menezes Jordão.

Revista X: Como podemos entender o Letramento Crítico em aulas de línguas materna e estrangeiras nos dias atuais? Qual a sua importância no contexto do ensino básico no Brasil?

Clarissa: Eu entendo o LC como uma espécie de pedagogia crítica de viés pósestruturalista, o que parece uma contradição, mas pode ajudar a entender uma diferença importante entre as duas perspectivas que muitas vezes passa despercebida. Este viés parte dos pressupostos de que o mundo é um lugar de complexidade, a realidade é inacessível a nós sem a linguagem, nossas perspectivas são sempre de ordem interpretativa, construídas nos discursos que nos constituem e são por nós construídos. Tais pressupostos impedem a construção de modelos idealizados e generalizáveis, tanto de subjetividades quanto de metodologias de ensino. Assim, não se pode garantir quais serão os efeitos daquilo que fazemos, como eles vão impactar as pessoas e que desdobramentos terão: no máximo, podemos desejar certos efeitos, mas jamais teremos garantias. Por isso no LC a colaboração é tão importante - é preciso sair do papel de 
fonte do conhecimento e assumir nossa incompletude e a necessidade que temos de interagir a fim de podermos construir novos conhecimentos, encontrar soluções (sempre contingentes) para nossos problemas, vislumbrar alternativas de sujeito, de práticas, de vida enfim.

A importância disso no contexto do ensino básico no Brasil? Enorme. Destaco um aspecto apenas: a diversidade de nosso país, e consequentemente das práticas desenvolvidas, das efetivas e das possíveis localmente em cada região, cada município, cada escola, conforme as relações estabelecidas entre cada professora e professor, e delas e deles com cada aluna desse Brasil, e das alunas e dos alunos entre si. Tal diversidade imprime um grau de complexidade imenso às escolas, o que evidentemente inviabiliza a implementação de práticas homogêneas. É preciso colaboração entre formadoras e formadores de professoras e professores, delas e deles com suas alunas e seus alunos, com as comunidades, com os governos, com os espaços físicos e enunciativos, a fim de que se busquem práticas contextualmente adequadas e sensíveis aos espaços locais. O LC demanda justamente esse tipo de prática.

Revista X: Em que medida o Letramento Crítico propõe uma educação linguística transformadora?

Clarissa: Não entendo o LC como propondo práticas necessariamente "transformadoras". Transformar só pra ficar diferente pode não ser produtivo. Mas acredito que o LC, quando pensado em conjunto com filosofias educacionais como o construtivismo, a colaboração, o aprender fazendo, pode levar à transformação da perspectiva da docência como uma prática autômata de "aplicação de teorias", para uma perspectiva da docência como um espaço criativo, sensível aos contextos locais e globais, resistente a pensamentos únicos (lembrei do "Perigo de uma História Única", da Chimamanda Adichie ${ }^{6}$ ), totalizadores e inibidores de ações que considerem a contingencialidade dos espaços de enunciação.

\footnotetext{
${ }^{6}$ Palestra proferida para a organização TED em julho de 2009. Disponível em https://www.ted.com/talks/chimamanda_adichie_the_danger_of_a_single_story.
} 
Revista X: Não existe o risco dessa perspectiva de ensino ser apropriada pelo discurso hegemônico, e ser banalizada (tal como ocorreu com a abordagem reflexiva)?

Clarissa: Sem dúvida existe. Mas esse risco sempre está presente, até porque a visão de mundo do LC prevê a apropriação de discursos como uma prática necessária na construção de sentidos - então, ler o LC de forma hegemônica e tentar instaurá-lo como uma abordagem homogeneizadora seria perfeitamente possível. Entretanto, numa prática que insiste na reflexividade, ou seja, em perceber a si própria como uma construção, como uma ideologia, como uma perspectiva que se torna possível diante e em meio ao entrelaçamento de vários discursos específicos, ver-se apropriada por outros e ressignificada em outros espaços não pode ser considerado algo ruim. A mim acalenta a possibilidade de que tais apropriações sejam feitas sem deixar de lado a reflexividade, ou seja, a percepção crítica de que todos os discursos (inclusive os nossos, claro) são construídos e estão relacionados a determinadas visões de mundo, a determinados quadros de referência, muitas vezes conscientemente percebidos, outras não.

Revista X: O PNLD sugere que as coleções didáticas de ensino de línguas estrangeiras se pautem pelo Letramento Crítico. Quais são os limites e potencialidades dessa proposta?

Clarissa: Tudo depende do entendimento que se faz do LC. Nos editais do PNLD muitas vezes me parece que se está usando LC como sinônimo de Pedagogia Crítica. Em textos anteriores eu já elaborei em detalhes a distinção que vejo entre as duas práticas (AC, PC e LC: farinhas do mesmo saco?, No tabuleiro da baiana tem... LC? ${ }^{7}$ ), portanto vou me concentrar aqui sobre o LC em livros didáticos. Acredito que o LC pode ser uma perspectiva de referência para autores e autoras de LD, que desse modo buscam sempre a contextualização das atividades propostas, as razões para ensinar e aprender determinados conteúdos, os sentidos de "conteúdo" especialmente quando se trata de língua portuguesa e língua estrangeira, as construções discursivas que possibilitam considerar usos de língua como adequados ou inadequados, etc. Entretanto, se não houver discussão com os professores e as professoras, nada disso chega nas salas

\footnotetext{
${ }^{7}$ As referências destes textos encontram-se ao final da entrevista, na parte de referências.
} 
de aula. Isto, evidentemente, é verdadeiro para qualquer abordagem e qualquer material didático. A formação continuada constante é fundamental para o sucesso de qualquer prática pedagógica. Uma formação continuada pautada nos princípios do LC pode sim efetivar práticas críticas e agentivas, construindo com os professores e as professoras um senso de pertencimento à comunidade profissional, de legitimidade no exercício da docência, diminuindo os efeitos da síndrome do impostor (BERNAT, 2008) que acomete especialmente os brasileiros e brasileiras que ensinam língua estrangeira.

Revista X: Já faz mais de dez anos desde proposta de ensino por Letramento Crítico feita nas Orientações Curriculares para o Ensino Médio (OCEM). O que dessa proposta continua atual, e até que ponto chegou a ser implementada em sala de aula?

Clarissa: Não creio que se possa (ou se precise) "medir" o grau de implementação de uma proposta orientada pelo LC. As propostas nesta linha são feitas sob o pressuposto de que serão relidas, ressignificadas em cada contexto de uso. O LC se coloca mais como uma referência para o desenvolvimento de práticas locais, do que como proposta a ser implementada. De qualquer modo, acredito que o LC sempre será atual, pois insiste na necessidade de posicionamento crítico e reflexividade, chamando as pessoas para que se percebam como interpretadoras (não intérpretes, interpretadoras mesmo), como leitoras da palavra-mundo como nos mostraram Freire \& Macedo (1990). Assim, a prática de "ler, se lendo" (conforme apontada por Lynn Mario Menezes de Souza) não perde o momento. Não tenho como discutir se tal prática tem se instaurado pelas salas de aula deste imenso país. Mas ainda acho possível (e altamente desejável) que ela esteja ou venha a se instaurar.

Revista X: Quais seriam alguns desafios de formar professores de línguas para trabalhar na perspectiva do Letramento Crítico?

Clarissa: Acho que o principal desafio está na nossa dificuldade de lidar com a multiplicidade e heterogeneidade constitutivas da atividade humana. Essa multiplicidade, que também existe nos processos de formação de professores é extremamente positiva, até porque só na pluralidade se pode ser crítico, mas é também e por isso mesmo um desafio. Os formadores precisam sentir-se minimamente confortáveis na coexistência de inúmeras orientações formativas, precisam saber transitar por entre elas. E precisam, sobretudo, considerar os professores com quem 
trabalham como seres inteligentes, capazes de criar, de interagir, de pensar, de sentir sem isso, como disse Rancière (2004), não temos como nos relacionar uns com os outros de forma produtiva. A partir daí, estabelecem-se ações colaborativas, de parceria que, a meu ver, precisam se dar na dimensão da práxis, ou seja, partindo do pressuposto de que teoria e prática são integradas, e de que formadores e professores (afinal, somos todos professores, não é?) juntos podem melhorar o ensino-aprendizagem nas escolas e fora delas. Para mim é fundamental termos sempre em mente a contingencialidade de nossas práticas, a noção de que elas se constroem em contextos específicos, por e para pessoas específicas, dentro de estruturas sociais, cognitivas, emocionais também específicas. Esses contextos, entendidos de forma ampla como a conjunção de vários elementos para além dos "espaciais", precisam ser levados em conta quando fazemos nossos planejamentos, quando estabelecemos nossas metas, nossos objetivos. Levar em conta contextos pra mim significa considerar quem são e como se formaram as pessoas que habitam e informam tais contextos; significa conversar com elas (ouvi-las como seres pensantes que são) e agir em colaboração. Quando se pensa especificamente em professores de línguas estrangeiras, creio ser fundamental discutir a colonialidade das teorias e metodologias de ensino-aprendizagem de LE, perceber o quanto elas fogem de nossas necessidades e contextos, e quais as alternativas que podemos construir.

Penso muito na ideia de pós-método do Kumaravadivelu (2001) como uma alternativa à noção de método, ou seja, na problematização que ele fez sobre a necessidade de seguirmos uma metodologia específica (geralmente dentre as importadas) em nosso trabalho. Tomando essa ideia como guia, trabalhar com noções de proficiência dentro de uma perspectiva translingual como a do Canagarajah (2014) pode ajudar a construir subjetividades e práticas com impacto bastante positivo em nossas salas de aula. Nessa perspectiva, os sentidos não estão nas formas linguísticas, nas estruturas gramaticais: os sentidos estão nas situações de uso, nos momentos concretos em que a língua é trazida à existência pelas pessoas. É preciso aprender e ensinar procedimentos de construção de sentidos. É preciso que as pessoas se sintam agentes na língua, capazes de comunicar. As melhores formas de desenvolver isso precisam ser elaboradas localmente, de modo a atender as especificidades não apenas de quem aprende, mas também de quem ensina - ou melhor, como disse Freire, "ninguém ensina ninguém: as pessoas aprendem umas com as outras”. Assim, professores e formadores precisam colaborar, analisando contextos, limitações e possibilidades, e desenvolvendo juntos formas de ser e estar em seus espaços. Para mim é fundamental 
que negociemos nossas práticas e desejos com os contextos em que existimos. Mais do que rupturas revolucionárias, que correm o risco de se tornarem tão autoritárias e totalizantes quanto as práticas com as quais romperam em primeiro lugar, acho que precisamos de ações subversivas, pontuais, que "contrabandeiem" no sistema imposto práticas diferentes, práticas que demonstrem a possibilidade da diferença, a produtividade de se existir em meio à diversidade. Seria, como diriam os pensadores da decolonialidade latino-americana (Mignolo, Quijano, Walsh, e outros ${ }^{8}$ ), uma forma de combater a violência epistêmica através da inserção, na lógica hegemônica, de outras lógicas que ela silencia.

\section{REFERÊNCIAS:}

BRASIL, Ministério da Educação. Secretaria de Educação Básica. Orientações Curriculares para o Ensino Médio: linguagens, códigos e suas tecnologias. Brasília: SEB/MEC, 2006.

BERNAT, E. Towards a pedagogy of empowerment: the case of 'impostor syndrome' among pre-service non-native speaker teachers in TESOL. ELTED, v.11, p.1-8, 2008.

BROWN, K. Developing critical literacy. Sydney, Australia: National Centre for English Language Teaching and Research, 1999.

BUMS, A.; HOOD, S. (Eds.). Teachers' voices 3: teaching critical literacy. Sydney: National Centre for English Language Teaching and Research, 1998..

CANAGARAJAH, A. S. Translingual practice: Global Englishes and cosmopolitan relations. New York: Routledge, 2013.

CERVETTI,G.; PARDALES, M. J.; DAMICO, J. S. A tale of differences: Comparing the traditions, perspectives and educational goals of critical reading and critical literacy. Reading Online, [S.I.], v.4, n. 9, 2001. Disponível em: https://resources.oncourse.iu.edu/access/content/user/mikuleck/Filemanager_Public_Fil es/L501/Unit\%201\%20Definitions/Cervetti,\%20et.\%20al\%20_2001_.docx. Acesso em: 10 de maio de 2017.

DUBOC, A. P. M Atitude Curricular: letramentos críticos nas brechas da formação de professores de inglês. 246 f. Tese (Doutorado em Estudos Linguísticos e Literários de inglês) - Universidade de São Paulo, São Paulo, 2012.

EDMUNDO, Eliana Santiago. O ensino de inglês na escola pública sob a perspectiva do letramento crítico. 241 f. Dissertação (Mestrado em Letras, Estudos Linguísticos) Universidade Federal do Paraná, Curitiba, 2010.

\footnotetext{
${ }^{8}$ Clarissa Jordão se refere à obra destes autores como um todo, nenhum título em particular.
} 
FREIRE, P.; MACEDO, D. Alfabetização: leitura do mundo leitura da palavra. São Paulo: Paz e Terra, 1990.

HAMMOND, J.;MACKEN-HORARIK, M. Critical literacy: Challenges and questions for ESL classrooms. TESOL Quarterly, 33, 528-544, 1999.

JORDÃO, C. M.; FOGACA, F. C. Ensino de Inglês, Letramento Crítico e Cidadania: um triângulo amoroso bem-sucedido. Línguas \& Letras (UNIOESTE), v. 8, p. 79-105, 2007.

JORDÃO, C. M.. O que todos sabem.... ou não: letramento crítico e questionamento conceitual. Crop (FFLCH/USP), v. 12, p. 21-46, 2007.

JORDÃO, C. M.. No Tabuleiro da Professora Tem.... Letramento Crítico?. In: . JESUS, D. M. de; CARBONIERI, D. (Org.). Práticas de Multiletramentos e Letramento Crítico: outros sentidos para a sala de aula de línguas. 1ed. Campinas: Pontes Editores, 2016, v. 1, p. 41-56.

JORDÃO, C. M.. Abordagem comunicativa, pedagogia crítica e letramento crítico ? farinhas do mesmo saco?. In: HILSDORF ROCHA, C.; MACIEL, R. (Org.). Língua Estrangeira e Formação Cidadã: entre discursos e práticas. 1ed.Campinas: Pontes, 2013, v. 1, p. 37-54.

KUMARAVADIVELU, B. Toward a postmethod pedagogy. TESOL Quarterly 35, p. 537-60, 2001.

LANKSHEAR, C.; MCLAREN, P. Critical Literacy: Politics, Praxis and the Postmodern. Albany, NY: State University of New York Press, 1993.

LANKSHEAR, C.; KNOBEL, M. (1998). Critical Literacy and New Technologies. Paper presented at the American Education Research Association. San Diego, 1998. Disponível em: http://everydayliteracies.net/files/critlitnewtechs.html. Acesso em: $10 \mathrm{de}$ maio de 2017.

LUKE, A. Critical approaches to literacy. In: EDWARDS, V.; CORSON, D. (Eds.), Encyclopedia of Language and Education, Volume 2: Literacy, 1997, p. 143-152.

MONTE MOR, W.. Letramento crítico: Linguagem como prática social. In: III Jornada de Letras das Faculdades Hoyler, 2005, Cotia, SP, 2005.

MORGAN, W. Critical literacy in the classroom: The art of the possible. New York: Routledge, 1997.

RANCIÈRE, J. O mestre ignorante - cinco lições sobre a emancipação intelectual. Tradução de Lilian do Valle. $2^{a}$ ed. Belo Horizonte: Autêntica, 2004.

SHOR, I. What is Critical Literacy? Journal for Pedagogy, Pluralism \& Practice, 1(4), 1999. Disponível em: http://www.lesley.edu/journals/jppp/4/shor.html. Acesso em: 01 de maio de 2017.

SOUZA, L. M. T. M..; ANDREOTTI, Vanessa . Critical Literacy in Global Citizenship Education. 2. ed. Derby, Inglaterra: Global Education, Derby, 2008. v. 1. 24p

SOUZA, L. M. T. M.. Para uma redefinição de letramento crítico: conflito e produção de significação. In: Maciel, R.F \& Araújo, V.A.. (Org.). Formação de Professores de Línguas: ampliando perspectivas. Jundiai: Paço Editorial, 2011, v. 1, p. p.128-140. 